\title{
Spatio-temporal analysis of the occurrence of human visceral leishmaniasis in Araçatuba, State of São Paulo, Brazil
}

\author{
Patricia Marques Moralejo Bermudi ${ }^{[1]}$, Marluci Monteiro Guirado ${ }^{[2]}$, \\ Lilian Aparecida Colebrusco Rodas ${ }^{[3]}$, Margareth Regina Dibo ${ }^{[4]}$ \\ and Francisco Chiaravalloti-Neto ${ }^{[5]}$
}

\begin{abstract}
[1]. Programa de Pós-Graduação em Saúde Pública, Faculdade de Saúde Pública, Universidade de São Paulo, São Paulo, SP, Brasil. [2]. Laboratório de Vetores de São José do Rio Preto, Superintendência de Controle de Endemias, São José do Rio Preto, SP, Brasil. [3]. Serviço Regional 9, Superintendência de Controle de Endemias, Araçatuba, SP, Brasil.

[4]. Laboratório de Entomologia, Superintendência de Controle de Endemias, São Paulo, SP, Brasil.

[5]. Departamento de Epidemiologia, Faculdade de Saúde Pública, Universidade de São Paulo, São Paulo, SP, Brasil.
\end{abstract}

\begin{abstract}
Introduction: This study aimed to describe the occurrence of human visceral leishmaniasis in Araçatuba with regard to time and space and to identify high risk areas. Methods: We included all human visceral leishmaniasis autochthonous cases reported between 1999 and 2015. The incidence rates were calculated by sex, age, and year. The human visceral leishmaniasis cases were geocoded and grouped by urban census tracts, enabling the calculation of the incidence and mortality rates by census tracts. For the identification of high risk areas, we utilized the scan statistics and univariate Ripley's K-function. Results: The incidence presented a cyclic pattern in 1999-2009, with peaks in 2002 and 2007 (30.1 and 19.6 cases per 100,000 inhabitantyears, respectively). In 2010-2015, the incidence remained relatively stable with about 2.0 cases per 100,000 inhabitant-years. The scan statistics detected two spatial clusters of high risk and three spatio-temporal clusters of high risk that lasted from 2001 to 2008. A spatial autocorrelation was observed in the human visceral leishmaniasis case point distribution in 1999-2009. No spatio-temporal clusters and no spatial autocorrelation in the case point pattern were identified in 2010-2015. Conclusion: We identified a changing pattern of human visceral leishmaniasis occurrence in Araçatuba: the first period (1999-2009) showed a cyclic pattern, clusters, and presence of spatial dependence in the case point distribution; the second period (2010-2015) showed the lowest rates of all historical series, stable incidence, and cases with a random distribution pattern.
\end{abstract}

Keywords: Human visceral leishmaniasis. Temporal analysis. Spatial and spatio-temporal analysis. Brazil.

\section{INTRODUCTION}

Until 1998, human visceral leishmaniasis (HVL) cases reported in the State of São Paulo (SP) were imported from other Brazilian regions, and its principal vector, Lutzomyia longipalpis, was detected only in rural areas in the eastern part of the State ${ }^{1}$. Lu. longipalpis was first detected in 1997 in the urban areas of Araçatuba City². In 1998, autochthonous cases of canine visceral leishmaniasis (CVL) were detected, and in 1999, the first autochthonous HVL cases were also detected ${ }^{3}$.

Studying the temporal and spatial distribution of HVL in Araçatuba was important because it was the first municipality of the state to confirm autochthonous cases and it had played

Corresponding author: Prof. Francisco Chiaravalloti-Neto.

e-mail: franciscochiara@usp.br

Received 20 January 2018

Accepted 3 July 2018 an important role in the dissemination of the disease in $\mathrm{SP}^{4}$. Furthermore, the dissemination of the disease in Araçatuba in the early years after its introduction occurred without a structured surveillance and control program in SP. The use of geographic information systems (GIS) and spatial analysis tools are important to evaluate the geographical distribution of the disease. The results of the analyses using these tools help in the understanding of health-related phenomena and are important when deciding on the surveillance and control measures, allowing the identification of areas of greatest risk for its occurrence ${ }^{5,6}$.

Thus, this study aimed to describe the occurrence of HVL in Araçatuba with regard to time and space, between 1999 and 2015, and to identify high risk areas.

\section{METHODS}

The municipality of Araçatuba $\left(21^{\circ} 12{ }^{\prime} 32^{\prime}\right.$ S, $\left.50^{\circ} 25^{\prime} 58^{\prime \prime} \mathrm{W}\right)$ is the capital city of the region with the same name localized in 
the Western part of SP, along the border with the Mato Grosso do Sul State, Brazil (Figure 1). It is situated at an altitude of $398 \mathrm{~m}$ a.s.l. in a region with tropical climate. This study was a descriptive and ecological study.

We included all HVL autochthonous cases reported between 1999 and 2015 in Araçatuba, with the following information: date of onset of symptoms, age, sex, address, occurrence of death, and HIV infection. The data were obtained from the Notifiable Diseases Information System [Sistema de Informação de Agravos de Notificação (SINAN)] database. The HVL cases were geocoded by address and grouped by urban census tracts.

Incidence rates (IR) and mortality rates (MR), standardized by age, fatality rates (FR), and HIV coinfection rates (CR) were calculated for the entire study period. The IR was also analyzed by age, sex, and year. Once the HVL cases were grouped by census tracts, we calculated the values for IR and $\mathrm{MR}$, standardized by age, for each census tract for the entire period of study. Data about the year of occurrence of HVL cases, census tracts, and year when the first case occurred in each census tract were depicted in thematic maps.

The scan statistics ${ }^{7}$, using SaTScan 9.3.1 software $^{8}$, was performed to identify spatial and spatio-temporal clusters that are high risk for HVL. Three databases were created: the first database contained the data of each case, such as census tracts, date of onset of symptoms, and age of the case; the second database contained information about the number of inhabitants for each census tract by age; and the third database contained the Cartesian coordinates of the census tract.

For the identification of purely spatial clusters, we used the Poisson discrete model with the following conditions: period between 1999 and 2015, no occurrence of geographical overlap, maximum size equal to $50 \%$ of the exposed population, circular shape, and 999 replications to calculate the $\mathrm{p}$ values. For the identification of spatio-temporal clusters, we also used the Poisson model with the same conditions for the spatial analysis, considering the time precision in years and the maximum size of the temporal cluster equal to $50 \%$ of the total period. These conditions provided results controlled by the census tract population and their age distribution?

To evaluate the existence of spatial dependence between distributions of human cases in the study area, univariate analyses of the three periods were performed using Ripley's K-function: 1999-2004, 2005-2009, and 2010-2015. Results showed that the first two periods presented the highest rates of

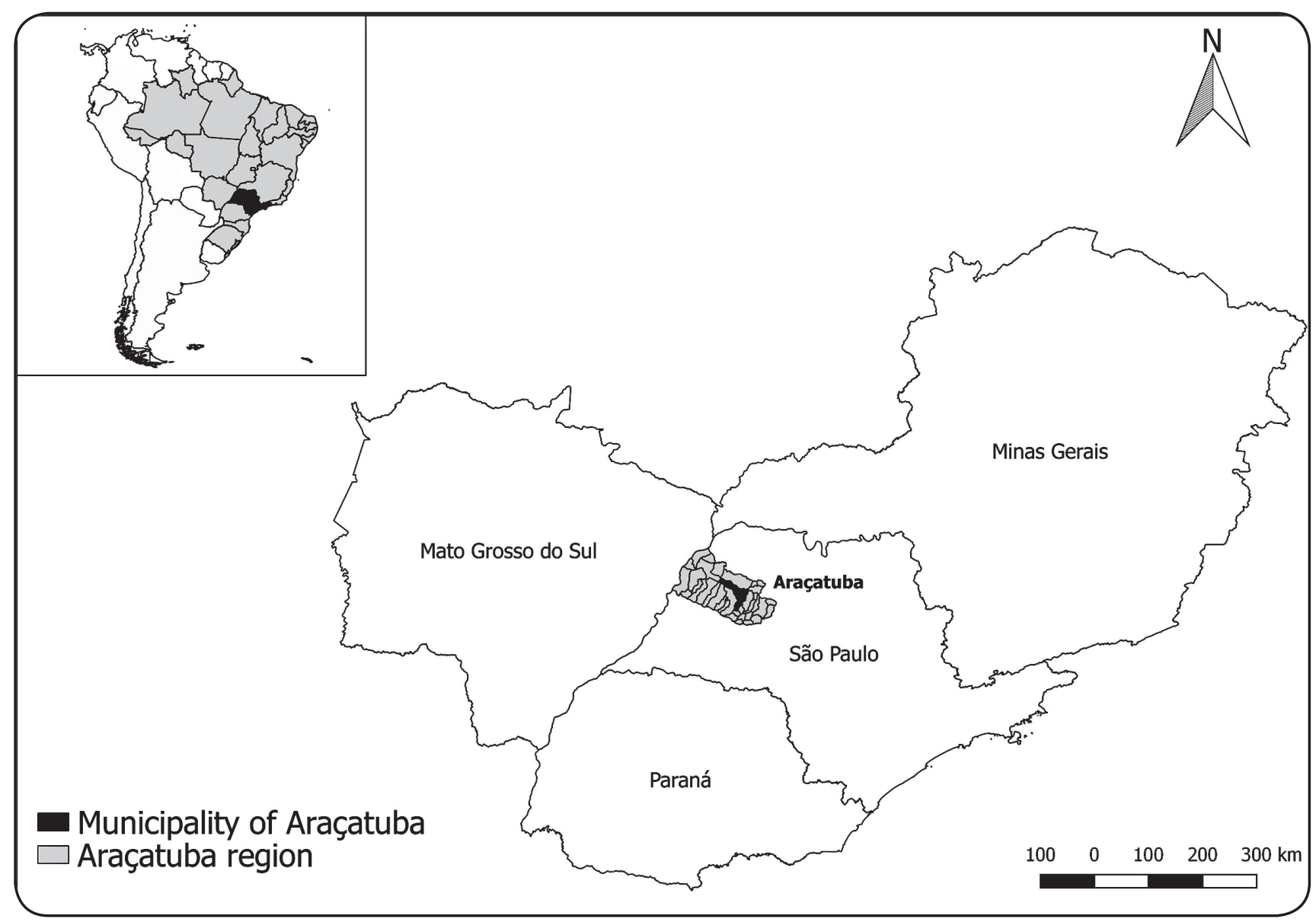

FIGURE 1: Map of South America with the Brazilian states, highlighting the São Paulo State (top left). São Paulo State with its three border States (Paraná, Minas Gerais, and Mato Grosso do Sul) highlighting the municipality and region of Araçatuba (main map). 
disease, each presented with a peak, and the last period had the lowest and relatively stable rates.

Three banks with the geographical coordinates of each case in different periods were used, through software $\mathrm{R}$ version 3.2.3 ${ }^{9}$. Graphs of the curves of the function $\mathrm{K}$ were generated according to distance in meters, with $95 \%$ confidence interval. No significant dependence was found when the function did not exceed any limit in any distance, a positive dependence was found when it exceeded the upper limit, and a negative dependence was found when it exceeded the lower limit.

\section{Ethical considerations}

The present study was approved by the Research Ethics Committee from the School of Public Health of the University of São Paulo (protocol number: 257.511; 04/26/2013).

\section{RESULTS}

There were 315 confirmed autochthonous cases of HVL and 30 deaths from HVL in Araçatuba, from 1999 to 2015. In the entire study period, the IR, MR, and FR were 10.2 cases per 100,000 inhabitant-years (12.7 for men and 8.2 for women), 1.0 death per 100,000 inhabitant-years, and $9.5 \%$, respectively. The IR for ages between 0 and 4 years were much higher than that for the other age groups. By sex, female patients aged 0-4 years had higher IR than male patients. In other groups, male patients had higher IR than female patients (Figure 2A). Among the HLV cases, we identified 35 HIV coinfections, which corresponded to 1.1 cases per 100,000 inhabitant-years.

Figure 2B presents the IR by year, and it can be seen that the first incidence peak occurred in 2002 (30.1 cases per 100,000 inhabitant-years, the highest rate registered in all temporal series). This peak was followed by a reduction in the rates until 2005 and thereafter another increase until 2007 (second peak: 19.6 cases per 100,000 inhabitant-years). Subsequently, the rates diminished until 2010. Between 2010 and 2015, the IR stabilized at 2.0 cases per 100,000 inhabitant-years. The IR values in this last period were the lowest of the all temporal series. We emphasized that the CR incidence curve by year followed the pattern of the IR curve in the period, but at a much lower level.

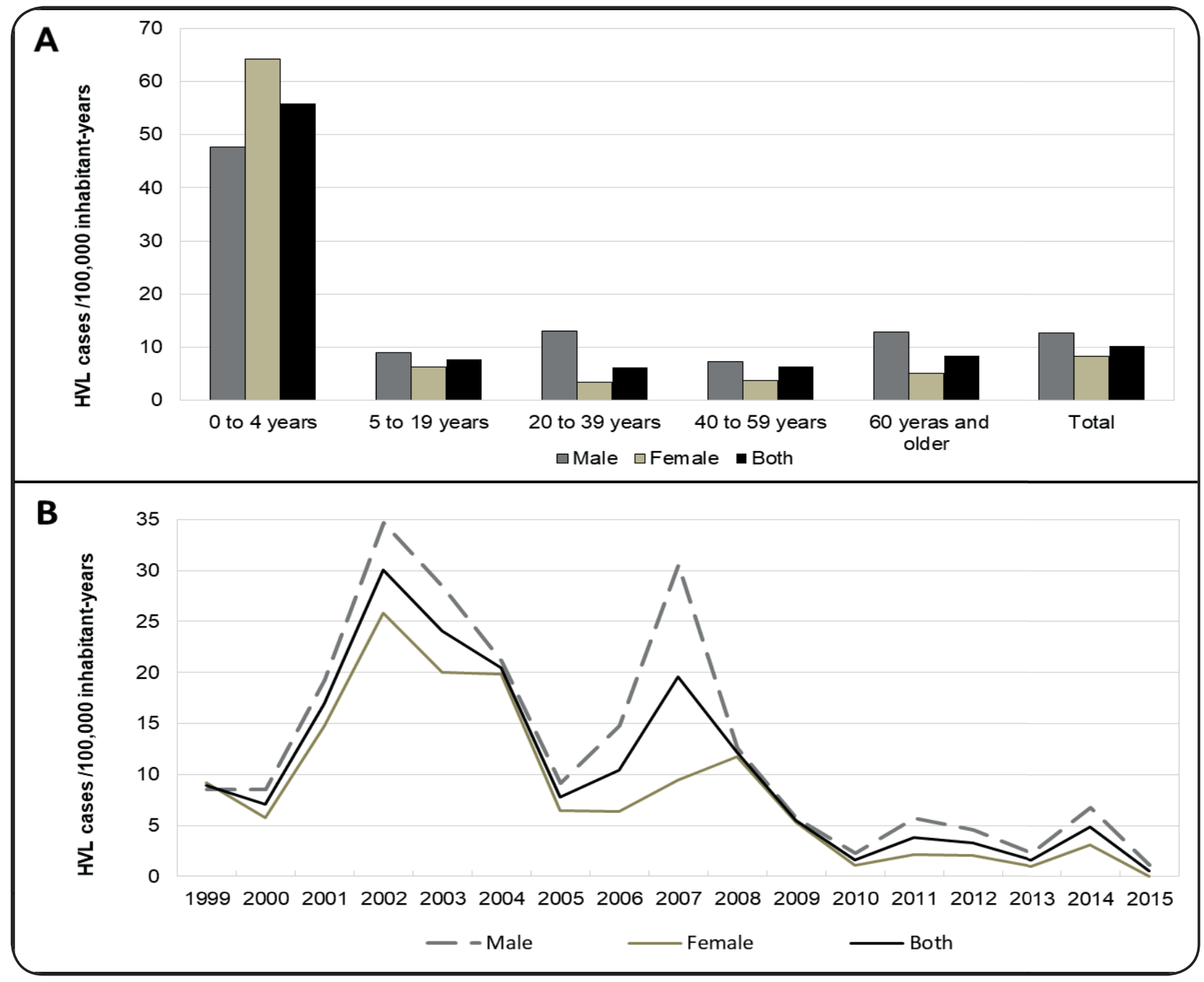

FIGURE 2: A. Total incidence of HVL and incidence of HVL by gender, standardized by age. B. Total incidence and incidence by gender (standardized by age), by year. Araçatuba, São Paulo State, Brazil, 1999-2015. HVL: human visceral leishmaniasis. 
It was possible to geocode $311(98.7 \%)$ of the $315 \mathrm{HVL}$ cases. Figure 3 presents the map of the urban area of the city with the HVL cases that were geocoded by year of occurrence and the census tract by year of occurrence of the first case. The census tract that corresponded to the geographic center of the city is pointed out in gray in Figure 3. The cases with the same address in the same thematic map were slightly spaced from each other so that every point on the map represented only one HVL case. The occurrence pattern of HVL cases during the entire study period was only one case by census tract in the same year. The exception was the occurrence of more than one case by census tract in the same year.

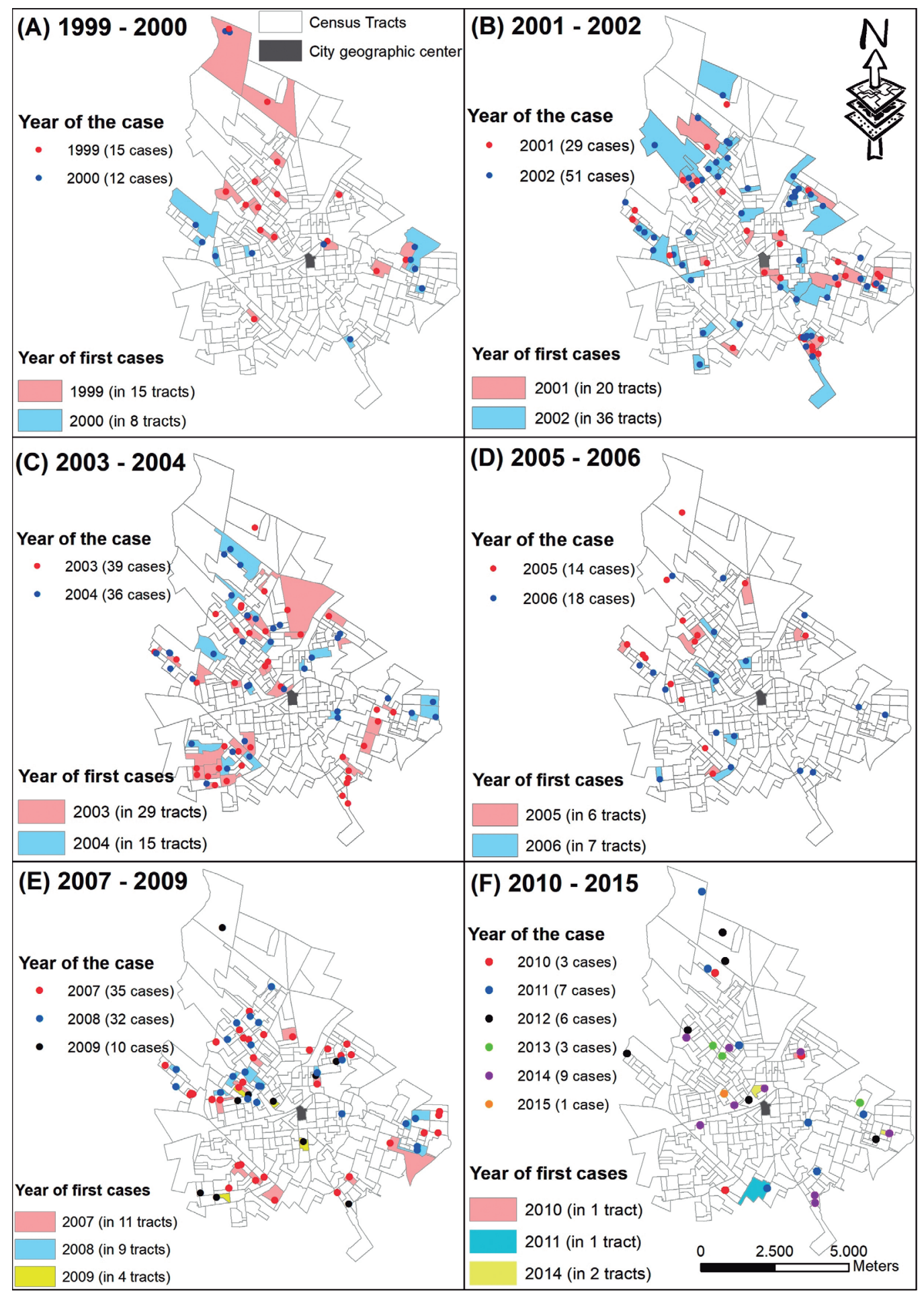

FIGURE 3: HVL cases according to location and year of occurrence; urban census sectors according to year of occurrence of the first HVL cases; urban area of Araçatuba, São Paulo State, Brazil, 1999-2015. HVL: human visceral leishmaniasis. 
In 1999-2000, 27 HVL cases occurred in 23 census tracts in Araçatuba. The cases were dispersed in the norther part of the city; however, the cases formed a cluster in the eastern part of the city (Figure 3A). The periods 2001-2002 and 2003-2004 experienced the greatest numbers of case ( 80 and 75 , respectively), and the greatest numbers of census tract with transmission was detected for the first time (56 and 44, respectively). In the first period (2001-2002), the cases were more concentrated in the peripheral areas than in the central area; however, a cluster of cases around the geographic center was also observed (Figure 3B). In the following period (2003-2004), the occurrence of cases in the region above the geographic center was similar to that reported in 1999-2000. In the region below the geographic center, a new cluster had formed in the southwestern area (Figure 3C).

In 2005 and 2006, there was a significant decrease in the number of HVL cases (32) and in the number of census tracts affected by the disease for the first time (13). Furthermore, the disease had spread throughout the city, excluding the area near the geographic center (Figure 3D). In the following two years (2007-2008), the occurrence of the disease became more intense, with 67 new HVL cases and 20 census tracts presented for the first time; however, in 2009, there was again a decrease in the incidence, with only 10 cases reported. In 2007-2009, the disease had spread in the region above the geographic center, but without reaching the extreme northern part of this area. In the region below the geographic center, clusters of cases occurred in both the far Southeastern and Southwestern part of this area (Figure 3E). The last period (2010-2015), despite covering 6 years, had the lowest number of census tracts with cases for the first time (only 4 and only 29 HVL cases), with the disease spreading throughout the urban area of the city (Figure 3F).

The initial occurrence of one or few cases in certain areas of the city giving rise to clusters of cases followed by its dissipation in the following years was the pattern of the spatial distribution of HVL in Araçatuba. For example, the region located in the extreme Southwestern part of the city had one case in 1999, one case in 2001, three cases in 2002, and the formation of a cluster of $16 \mathrm{HVL}$ cases in 2003-2004.

The map of the urban area of Araçatuba by census tract showing the IR and MR values for the entire study period and its geographic center is presented in Figure 4A and Figure 4B. If we divided the city into parts above and below the geographic center, it can be seen that in the part above there were more census tracts with the occurrence of disease and with higher incidences (red and green colors) compared with the part below. Furthermore, the occurrence of disease in the region above the geographic center presented a more spread pattern than the region below it, with the presence of clusters in the Southeast, extreme South, and Southwest areas (Figure 4A). The MR presented a more uniform spatial pattern than the IR. It should be noted that, in general, no deaths were identified in areas with the highest incidence (Figure 4B).

The result of the analysis to identify spatial clusters of HVL cases is presented in Figure 4C, with two clusters identified. The first cluster (spatial cluster 1) encompassed the upper half part of the city and the second (spatial cluster 2) was localized in its Southern part. The relative risks (RR) for HVL related to clusters 1 and 2 were 2.0 and 3.6, respectively.

The result of the analysis to identify spatio-temporal clusters of HVL cases, with the same controls used for the spatial clusters, is presented in Figure 4D, with three clusters identified in 2001-2008. The first cluster (spatio-temporal cluster 1) lasted from 2001 to 2003 and corresponded to the spatial cluster 1; the second cluster (spatio-temporal cluster 2) lasted from 2002 to 2008 and corresponded to the spatial cluster 2 . The spatiotemporal cluster 3 lasted from 2003 to 2004 and was located in the southern part of the city. This cluster did not correspond to the identified clusters detected in the purely spatial analysis, because its incidence did not present high values in the entire period, but only in 2003 and 2004. The RR associated with these clusters were 10.3, 3.3, and 5.4 for clusters 1, 2, and 3, respectively.

With regard to the spatial dependence of the distribution of cases, it was observed in 1999-2004 (Figure 5A) and 20052009 (Figure 5B) that the highest agglomeration of cases occurred between $800 \mathrm{~m}$ in the first period and $1,000 \mathrm{~m}$ in the second period. In the period 2010-2015 (Figure 5C), no spatial dependence was observed at any distance.

\section{DISCUSSION}

The highest HVL incidence rates in Araçatuba from 1999 to 2015 occurred among the youngest age group (0-4 years). The incidence rates over the study period indicated a changing pattern of occurrence: the first period (1999 to 2009) presented a cyclic pattern, clusters, and presence of spatial dependence in the case point distribution; the second period (2010 to 2015) presented the lowest rates of all historical series, stable incidence, and HVL cases with a random distribution pattern. We hypothesized that this changing pattern could be a consequence of the development of control measures, an issue that will be the subject of future investigation.

High risk regions were identified in the study period, but no deaths were noted, probably due to the underreporting of these cases. In a study using capture and recapture, Maia-Elkhoury et al. ${ }^{10}$ estimated that $45 \%$ of HVL-related deaths registered in the Mortality Information System [Sistema de Informações sobre Mortalidade (SIM)] were not registered in the SINAN database. In addition, the random fluctuation of the data, caused by the phenomenon of small numbers due to the low number of deaths by census tracts, should be considered.

The temporal and spatio-temporal analyses showed that the period between 1999 and 2009 encompassed the years with spatio-temporal clusters (2001-2008), the years (2002 and 2007) where the disease had its peaks, and the years with the highest incidence rates. The results of the Ripley's K-function followed the same direction, as the HVL case point distribution presented a positive spatial autocorrelation in the period 1999 2009. In 2010-2015, no spatio-temporal clusters were detected and no spatial dependence was observed at any distance in the point pattern analysis, which coincides with the period of low rates and relative stability in the incidence. 


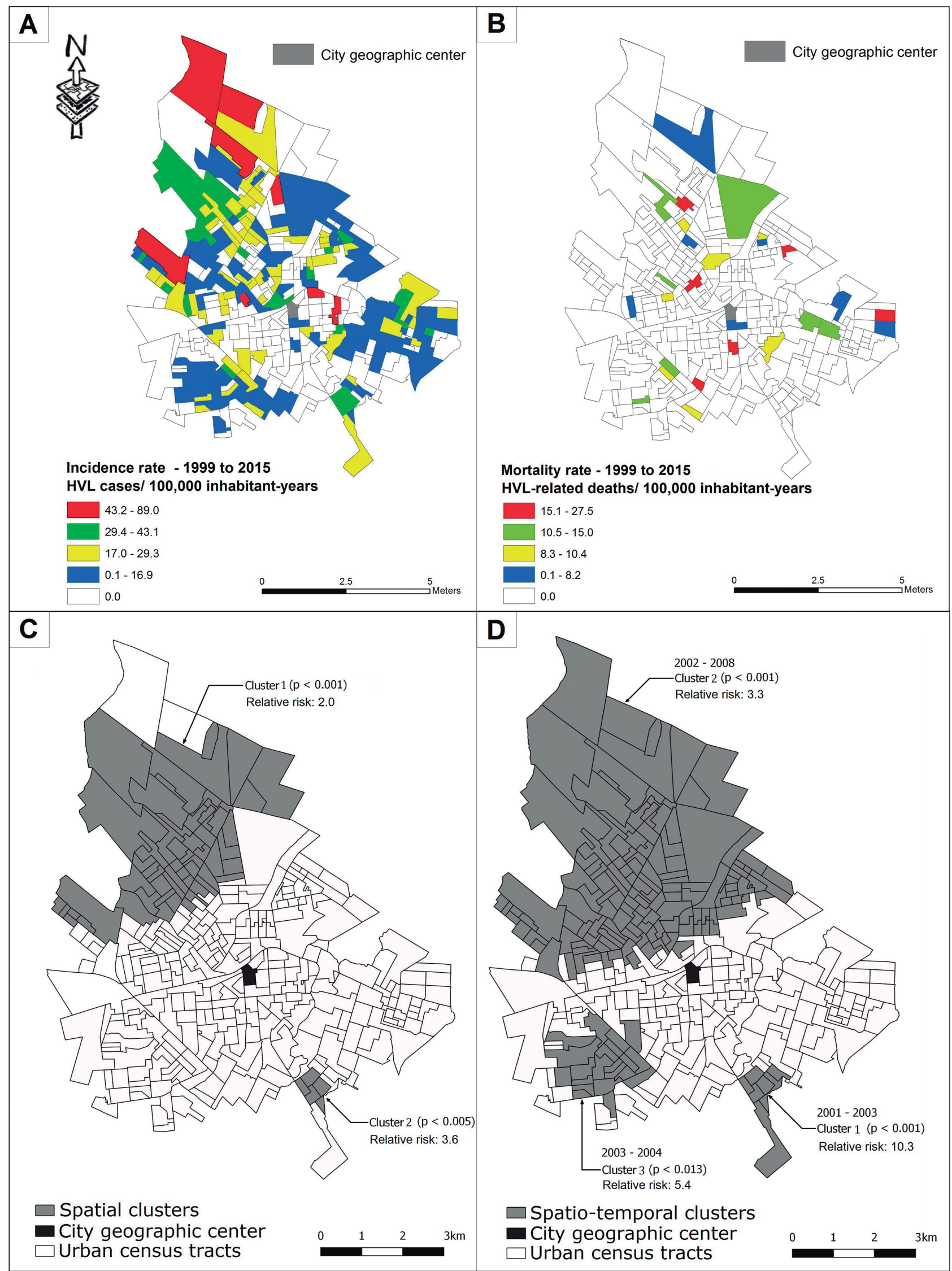

FIGURE 4: Incidence (A) and mortality (B) rates by age-adjusted HVL cases according to census tracts, spatial cluster (C), and spatiotemporal cluster (D), controlled by census tract population and age distribution; urban area of Araçatuba, São Paulo State, Brazil, $1999-2015$. HVL: human visceral leishmaniasis. 
(A)

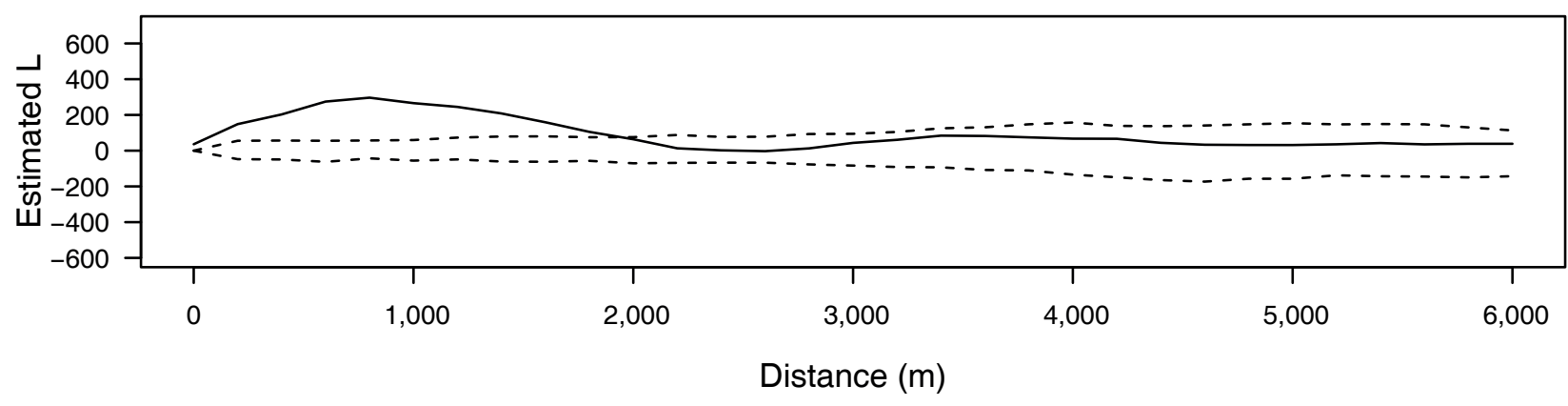

(B)

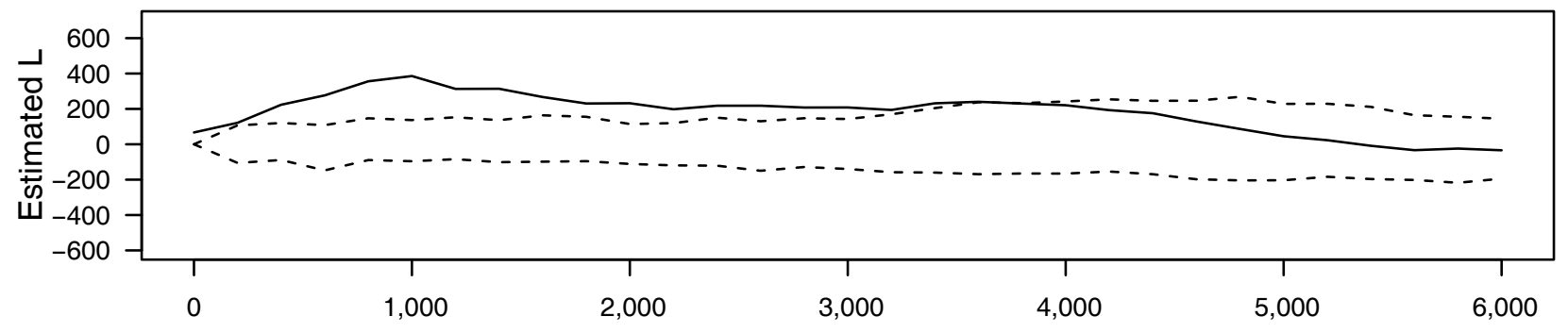

Distance $(m)$

(C)

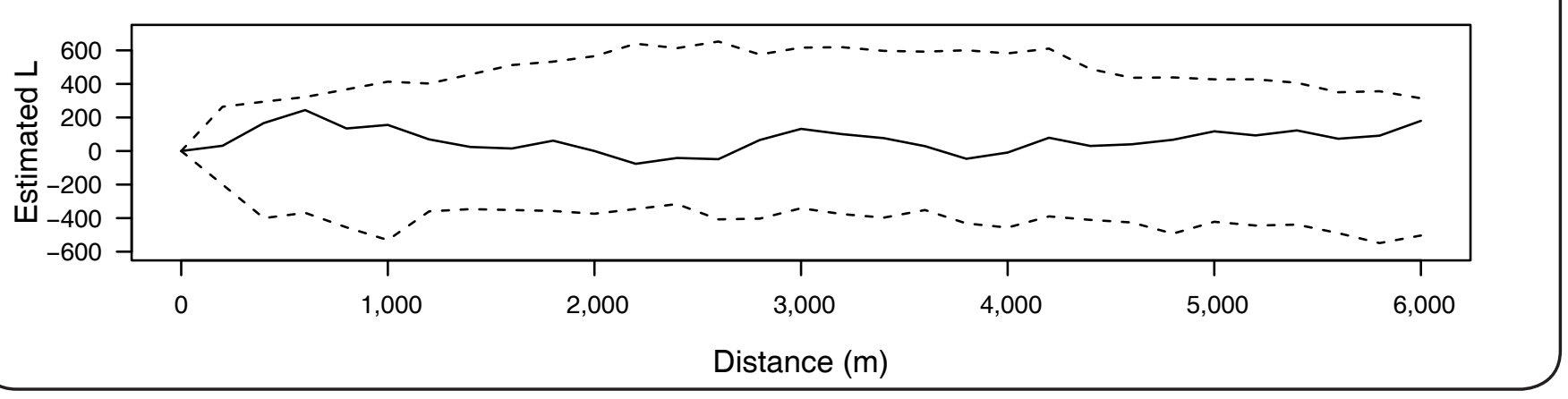

FIGURE 5: Ripley's univariate K-function analysis: 1999-2004 (A), 2005-2009 (B), and 2010-2015 (C), Araçatuba, São Paulo State, Brazil.

Similar to a previous study conducted in Araçatuba, Souza et al. ${ }^{11}$, Vieira et al. ${ }^{12}$, and Cardim et al. ${ }^{13}$ performed a spatial and spatio-temporal analysis of HVL in the Cites of Bauru, Birigui, and Adamantina, SP and clusters were detected. Furthermore, Ripley's K-function was applied in a study on CVL and HVL occurrence in the City of Araçua, Minas Gerais State, Brazil ${ }^{14}$. We expected that the highest agglomeration distance of HVL cases is about $250 \mathrm{~m}$, based on the phlebotomine flight radius that, in urban areas, hardly exceeds this distance ${ }^{15}$. However, other factors related to the reservoir, environment, and humans may be involved in the composition of the HVL distance agglomeration, which could explain the findings of our study.

Apart from the results of our study, it is worth noting that the use of scan statistics allowed the identification of clusters that represent the risk areas, which should be prioritized in relation to the adoption of surveillance and control activities. As for the spatio-temporal clusters, in a retrospective analysis, they represent areas that presented conditions more favorable to transmission and therefore deserve further investigations. Although the use of Ripley's K-function in visceral leishmaniasis studies was limited, it is a useful tool to evaluate the existence of spatial dependence in point distributions and identify distances for control purposes.

With regard to conditions that caused HVL to be clustered, factors related to the vector, animal reservoir, and socioeconomic, demographic, and environmental conditions, among others, 
must be considered. The vector distribution is considered to be clustered ${ }^{16}$ and related to the HVL case occurrence ${ }^{17,18}$. CamargoNeves et al. ${ }^{19}$ studied the Northern region of Araçatuba, seeking to identify environmental determinants for establishment and maintenance of the vector. They observed that in one of the five sectors studied, there was a higher density of sand flies forming spatial clusters and higher presence of organic matter in the buildings with smaller backyards, compared with properties with backyards of greater size. With regard to the animal reservoir, Costa et al. (in press) ${ }^{20}$ observed in Araçatuba that the average prevalence of CVL from 2007 to 2015 in the areas where serological screening was conducted did not exceed $20 \%$ but it decreased between 2007 and 2009, with a relative stability around $6.8 \%$. Moreover, they also observed a significant spatial dependence between human and canine cases.

Fernández et al. ${ }^{17}$ studied the spatial distribution of Lu. longipalpis around sites where human cases were detected in the province of Misiones, Argentina, and found places with high vector density. Oliveira et al..$^{18}$ also found a significant association between the number of Lu. longipalpis collected and HVL and CVL occurrence in Três Lagoas, Mato Grosso do Sul State, Brazil. The relationship between areas with higher vector density and HVL clustering could also be presented in a reverse form. Once HVL high-risk clusters are detected, these areas should be prioritized when developing canine and vector control measures.

In a study carried out in West Africa, Kolaczinski et al. ${ }^{21}$ observed that the disease occurred in areas with low socioeconomic status. The highest rates of HVL incidence in Teresina, Piaui State, Brazil, occurred in areas with abundant vegetation cover, high population growth, and lack of adequate infrastructure ${ }^{22}$. Maia et al..$^{23}$ observed, in Petrolina, Pernambuco State, Brazil, that the highest number of CVL and HVL cases occurred in an area of this city with the worst socioeconomic conditions, which also had many street dogs. Borges et al. ${ }^{24}$ identified in Belo Horizonte, Minas Gerais State, Brazil, that the presence and number of dogs in every household were associated with an increased risk of HVL.

Considering that the HVL case distribution is mainly associated with areas with higher vector density ${ }^{16-18}$, higher canine presence and CVL prevalence ${ }^{11,14,24-28}$, and worse socioeconomic, demographic, and environmental conditions ${ }^{21-23}$, the HVL clustering would be seen as a consequence of all these conditions collectively.

With regard to the absence of HVL clustering in last period of our analysis (2010-2015) and the factors that could be linked to this, if higher vector density and canine prevalence and worse socioeconomic conditions could cause HVL clustering, then the inverse could be also true. However, there was no evidence to prove that the socioeconomic, demographic, and environmental characteristics have changed during the period of the study.

Thus, the changing pattern of the HVL incidence curve and absence of disease clustering in Araçatuba in the period between 2010 and 2015 could be a result of the application of control measures, even in areas of low coverage ${ }^{29}$. In Birigui, a City bordering Araçatuba, where the first case of HVL was detected in the same year as that in Araçatuba, the disease exhibited, almost in the same period, a different behavior, with an increase in incidence in 2001 and two peaks in 2006 and $2011^{12}$. The divergence between HVL incidence observed in Araçatuba and Birigui, the two neighboring cities, may be related to the differences in coverage and quality of surveillance and control activities. However, this issue is still subject for future investigations, together with the evaluation of the relationship between coverage of control measures and HVL incidence in both cities.

In relation to the occurrence of the disease by age, a study in Bauru, SP, showed that $43 \%$ of the cases occurred in children under 10 years of age ${ }^{30}$. In the whole country, $54.4 \%$ of the HVL cases occurred in children aged below 10 years old, and $41 \%$ in children aged below 5 years $^{31}$. These results were similar to the findings of our study conducted in Araçatuba. These results can be explained by the fact that children are more susceptible to infections due to their immunological immaturity ${ }^{32}$. Regarding sex, it is expected that there was no difference in the incidence of HVL in people up to 19 years of age, or that there was a small predominance in men, and at 20 years of age or over, a predominance in men ${ }^{33}$. However, in Araçatuba, there was a higher incidence in female patients aged $0-4$ years, a result coincident with that obtained in Birigui ${ }^{12}$ and in a study conducted in Petrolina, Pernambuco State, Brazil ${ }^{34}$. With regard to the incidence of HVL in patients aged 20 years and over, Botelho and Nata ${ }^{33}$ found that in the City of Campo Grande, MS, the risk of developing HVL was higher in men, which similar to that observed in Araçatuba.

This study had some limitations. The use of data from the epidemiological surveillance conducted in Araçatuba probably caused the underreporting of cases, which would imply a change in the actual incidence rate of HVL. The fact that it was not possible to incorporate the data about the vector density and canine prevalence made the analysis less robust. Nevertheless, the identification of clusters of human cases, could contribute to public health decision making. Other positive aspects were the high proportion of cases that were geocoded and the use of GIS and spatial analysis tools that contributed to the identification of areas of risk and a changing pattern of the occurrence of the disease in Araçatuba.

\section{Conflict of interest}

The authors declare that there is no conflict of interest.

\section{Financial support}

This study was funded by the Fundação de Amparo à Pesquisa do Estado de São Paulo (FAPESP); Process no.: 2014/17764-6.

\section{REFERENCES}

1. Gomes AC, Galati EAB, Casanova C, Domingos MF, Marques GRAM, Camargo-Neves VLF. Analysis of the geographical distribution of leishmaniasis vectors in the state of São Paulo, Brazil. Bol Dir Malariol y San Amb. 1995;1:143-6. 
2. Costa IP, Casanova C, Rodas LAC, Galati EAB. Atualização da distribuição geográfica e primeiro encontro de Lutzomyia longipalpis em área urbana no Estado de São Paulo, Brasil. Rev Saúde Pública. 1997;31(6):632-3.

3. Camargo-Neves VLF, Spínola R, Lage L. A leishmaniose visceral americana no estado de São Paulo: situação epidemiológica em 2001-2002. Rev Soc Bras Med Trop. 2003;36(supl. II):27-9.

4. Oliveira AM, Vieira CP, Dibo MR, Guirado MM, Rodas LAC, Chiaravalloti-Neto F. Dispersal of Lutzomyia longipalpis and expansion of canine and humanvisceral leishmaniasis in São Paulo State, Brazil. Acta Trop. 2016;164:233-42.

5. Bailey TC. Spatial statistical methods in health. Cad Saúde Pública. 2001;17(5):1083-98.

6. Barbosa DS, Belo VS, Rangel MES, Werneck GL. Spatial analysis for identification of priority areas for surveillance and control in a visceral leishmaniosis endemic area in Brazil. Acta Trop. 2014;131:56-62.

7. Kulldorff M. A spatial scan statistic. Communications Statistics. Theory Methods. 1997;26(6):1481-96.

8. Kulldorff M. SaTScan Use Guide for version 9.3. 2014 (Accessed 2014 April 28). Available from: http://www.satscan.org. 122

9. R Core Team. R: a language and environment for statistical computing. Vienna, Austria: $\mathrm{R}$ Foundation for Statistical Computing; 2014. Available at: https://www.r-project.org/.

10. Maia-Elkhoury ANS, Carmo EH, Sousa-Gomes ML, Mota E. Análise dos registros de leishmaniose visceral pelo método de captura-recaptura. Rev. Saúde Pública. 2007;41(6):931-7.

11. Souza VAF, Cortez LRPB, Dias RAD, Amaku A, Ferreira-Neto JS, Kuroda RBS, et al. Space-time cluster analysis of American visceral leishmaniasis in Bauru, São Paulo State, Brazil. Cad Saúde Pública. 2012;28(10):1949-64.

12. Vieira CP, Oliveira AM, Rodas LAC, Dibo MR, Guirado MM, Chiaravalloti Neto F. Temporal, spatial and spatiotemporal analysis of the occurrence of visceral leishmaniasis in humans in the City of Birigui, São Paulo, Brazil, from 1999 to 2012. Rev Soc Bras Med Trop. 2014;47(3), 350-8.

13. Cardim MFM, Vieira CP, Chiaravalloti Neto F. Spatial and spatiotemporal occurrence of human visceral leishmaniasis in Adamantina, State of São Paulo, Brazil. Rev Soc Bras Med Trop. 2015;48(6):716-23.

14. Ursine RL, Dias JVL, Morais HA, Pires HHR. Human and canine visceral leishmaniasis in an emerging focus in Araçuaí, Minas Gerais: spatial distribution and socio-environmental factors. Mem Inst Oswaldo Cruz. 2016;111(8):505-11.

15. Brazil RP. The dispersion of Lutzomyia longipalpis in urban areas. Rev Soc Bras Med Trop. 2013;46(3):263-4.

16. Salomón OD, Feliciangeli MD, Quintana MG, Afontos MMS, Rangel EF. Lutzomyia longipalpis urbanisation and control. Mem Inst Oswaldo Cruz. 2015;110:831-46.

17. Fernández MS, Salomón OD, Cavia R, Perez AA, Acardi AS, Guccione JD. Lutzomyia longipalpis spatial distribution and association with environmental variables in an urban focus of visceral leishmaniasis, Misiones, Argentina. Acta Trop. 2010;114(2):81-7.

18. Oliveira GMG, Figueiró-Filho EA, Andrade GMC, Araújo LA, Oliveira MLG, Cunha RV. Flebotomíneos (Diptera:Psychodidae: Plebotominae) no município de Três Lagoas, área de transmissão intensa de leishmaniose visceral, estado de Mato Grosso do Sul, Brasil. Rev Pan-Amaz Saude. 2010;1(3):83-94.

19. Camargo-Neves VLF, Rodas LAC, Poletto DW, Latorre MRDO, Gomes AC. Estudo de fatores relacionados ao ambiente na distribuição de Lutzomyia longipalpis, no município de Araçatuba SP, Brasil. Rev Soc Bras Med Trop. 2002;35(Supl. III):97-102.

20. Costa DNCC, Bermudi PMM, Rodas LAC, Nunes CM, Hiramoro RM, Tolezano JE, et al. Visceral leishmaniasis in humans and relationships with vector and canine control measures. Rev Saude Publica. 2018;52. in press.

21. Kolaczinski JH, Reithinger R, Worku DT, Ocheng A, Kasimiro $\mathrm{J}$, Kabatereine N, et al. Risk factors of visceral leishmaniasis in East Africa: a case-control study in Pokot territory of Kenya and Uganda. Int J Epidemiol. 2008;37(2):344-52.

22. Cerbino-Neto J, Werneck GL, Costa CHN. Factors associated with the incidence of urban visceral leishmaniasis: an ecological study in Teresina, Piauí State, Brazil. Cad Saúde Pública. 2009;25(7):1543-51.

23. Maia CS, Pimentel DS, Santana MA, Oliveira GM, Pedrosa NA, Nascimento LA, et al. Análise espacial da leishmaniose visceral americana no município de Petrolina, Pernambuco, Brasil. Hygeia. 2014;10(18):167-76.

24. Borges BKA, Silva JA, Haddad JPA, Moreira EC, Magalhães DF, Ribeiro LML, et al. Presença de animais associada ao risco de transmissão da leishmaniose visceral em humanos em Belo Horizonte, Minas Gerais. Arq Bras Med Vet Zootec. 2009;61(5):1035-43.

25. Campos R, Santos M, Tunon G, Cunha L, Magalhães L, Moraes J, et al. Epidemiological aspects and spatial distribution of human and canine visceral leishmaniasis in an endemic area in northeastern Brazil. Geospat Health. 2017;12(1):67-73.

26. Lima ID, Queiroz JW, Lacerda HG, Queiroz PVS, Pontes NN, Barbosa JDA, et al. Leishmania infantum chagasi in northeastern Brazil: asymptomatic infection at the urban perimeter. Am J Trop Med Hyg. 2012;86(1):99-107.

27. Teixeira-Neto RG, Silva ES, Nascimento RA, Belo VS, Oliveira CDL, Pinheiro LC, et al. Canine visceral leishmaniasis in an urban setting of southeastern Brazil: an ecological study involving spatial analysis. Parasit Vectors. 2014;7:485.

28. Werneck GL, Costa CHN, Walker AM, David JR, Wand M, Maguire $\mathrm{JH}$. Multilevel modelling of the incidence of visceral leishmaniasis in Teresina, Brazil. Epidemiol Infect. 2007;135(2):195-201.

29. Costa DNCC, Codeço CT, Silva MA, Werneck GL. Culling dogs in scenarios of imperfect control: realistic impact on the prevalence of canine visceral leishmaniasis. PLoS Negl Trop Dis. 2013;7(8):e2355.

30. Ortiz RC, Anversa L. Epidemiologia da leishmaniose visceral em Bauru, São Paulo, no período de 2004 a 2012: um estudo descritivo. Epidemiol Serv Saúde. 2015;24(1):97-104.

31. Ministério da Saúde (MS). Secretaria de Vigilância em Saúde. Departamento de Vigilância Epidemiológica. Manual de Vigilância e Controle da Leishmaniose Visceral. 1 ${ }^{a}$ edição. Brasília: MS; 2014. 122p. Acesso em 7 de setembro de 2017. Disponível em: http:// bvsms.saude.gov.br/bvs/publicacoes/manual_vigilancia_controle_ leishmaniose_visceral_ledicao.pdf.

32. Xavier-Gomes LM, Costa WB, Prado PF, Oliveira-Campos M, Leite MTS. Clinical and epidemiological characteristics of visceral leishmaniasis in children hospitalized at a reference university hospital in the north of Minas Gerais, Brazil. Rev Bras Epidemiol. 2009;12(4):1-6.

33. Botelho ACA, Natal D. Primeira descrição epidemiológica da leishmaniose visceral em Campo Grande, Estado de Mato Grosso do Sul. Rev Soc Bras Med Trop. 2009;42(5):503-8.

34. Araujo AC, Gonçalves NNVM, Dantas-Torres F, Ferreira F, Horta MC. Visceral leishmaniasis in Petrolina, state of Pernambuco, Brazil, 2007-2013. Rev Inst Med Trop Sao Paulo. 2016;58:29. 